\title{
Cerebellar ataxia and ectodermal dysplasia in brothers
}

\author{
Michael Baraitser, William Reardon, Anthony McShane, John Wilson
}

\begin{abstract}
Two brothers are documented with an ectodermal dysplasia primarily involving the teeth and hair. Both have developed cerebellar ataxia in the early teens.

( $(\mathcal{H}$ Med Genet 1993;30:515-17)
\end{abstract}

The association of a cerebellar ataxia and an ectodermal dysplasia is unusual, and has only been reported in seven patients. ${ }^{1-3}$ Ectodermal features have generally been confined to hair and teeth with the cerebellar ataxia being later in onset and progressive in nature. The main additional clinical features have varied from one report to another and have included mental retardation, short stature, deafness, and hypogonadism. We now report a further sibship with this rare entity but with normal intelligence, and review this group of conditions.

\section{Case reports}

CASE 1

This boy was born at 37 weeks weighing $2722 \mathrm{~g}$ and had a normal neonatal period. He walked at 11 months, but spoke late and had only single words at the age of 2 years 4 months. When admitted to hospital at the age of 4 years for bilateral orchidopexy, a small triangular facies was noted (fig 1). The hair was thin and sparse and the primary dentition was very abnormal with eruption of only rudimentary teeth. At the age of 13 years he was noted to have difficulty riding a bicycle because of unsteadiness, and, on examination, he had bilateral pes cavus, scanning dysarthria, marked cerebellar incoordination involving both upper and lower limbs, and a gait which was wide based and stiff legged. Nystagmus was not present. Subsequent progression of his ataxia has been slow. Pyramidal tract involvement was evident from his bilateral extensor plantar responses and generally brisk reflexes, especially in the lower limbs. His abnormal teeth were again noted, his hair was soft and sparse, and his facial features remained unchanged (figs 2 and 3). Intelligence is unimpaired with normal school progress. Special investigations including EMG, EEG, VER, and ERG were normal. A CT brain scan showed the cerebellar sulci to be a little prominent, suggesting a slight possibility of atrophy. Other normal investigations included immunoglobulins, $\alpha$ fetoprotein, very long chain fatty acids, phytanic acid, and vitamin $K$. He is now receiving hormonal treatment for delayed puberty. Height and head circumference are towards the lower end of the normal range.
CASE 2

This brother of the proband was born to nonconsanguineous parents after a normal pregnancy and delivery, weighing $3317 \mathrm{~g}$. His early history was uneventful apart from surgical correction of bilateral inguinal herniae. Right orchidopexy was performed at 4 years (fig 4). Developmental milestones were normal, but at the age of 1 year it was commented that he had a "small triangular face, small teeth and poor hair growth". He was subsequently seen by one of us (MB) when he was just over a year old when the broad forehead and small triangular face was confirmed, and, given the sparse hair and hypodontia but normal sweating, it was suggested that an ectodermal dysplasia of uncertain type was the diagnosis. Re-evaluation at the age of 12 (fig 3), after his brother had begun to develop neurological signs, confirmed that he too was developing a cerebellar type tremor and ataxia. Height and head circumference are on the 25 th centile and intelligence is normal.

\section{Discussion}

Inherited cerebellar ataxias may be associated with clinical abnormalities in several other systems, ${ }^{4}$ but very rarely with ectodermal dysplasia. The seven cases in whom this com-

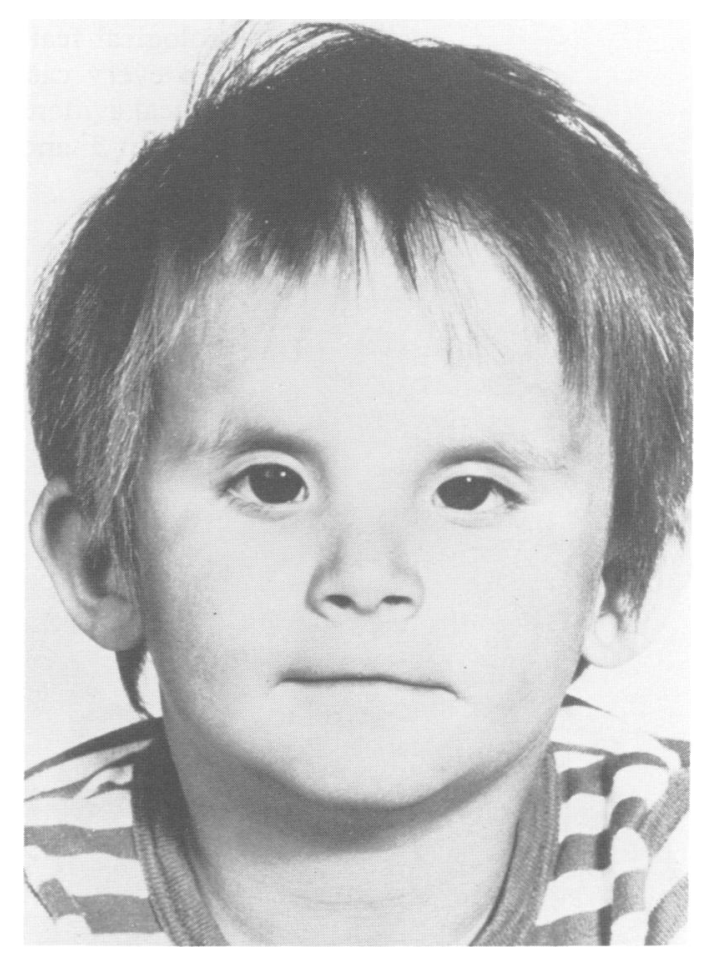

Figure 1 Case 1 aged 4. Note the sparse hair. 


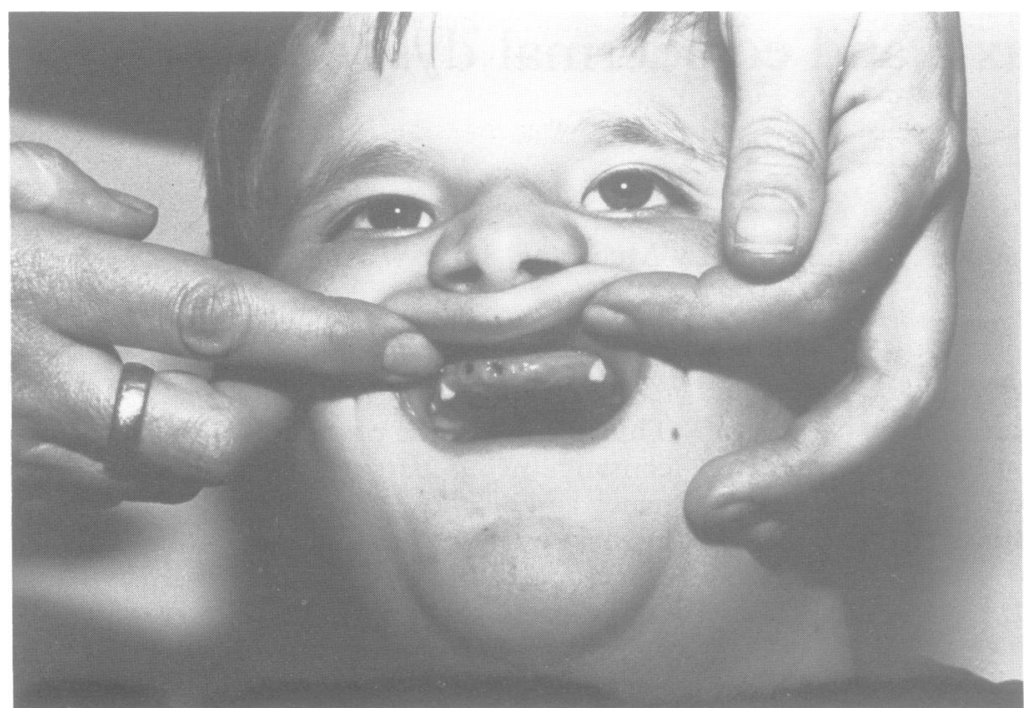

Figure 2 Hypodontia in case 1 aged 14.

bination of clinical features has been described comprise two sibships and a single case. The two children presented here are broadly similar to those reported and a comparison is shown in the table. As was the case in two reports, ${ }^{23}$ the children described here are of normal intelligence, whereas the brother and sister, offspring of a consanguineous union, described by Rushton and Genel ${ }^{1}$ were mentally retarded. This latter report also differs from the others in that there was deafness, short stature, and normal hair.

The other main areas of distinction relate to the age of onset of ataxia, the hypogonadism, and dental involvement. Based on the evidence of the clinical photographs, none of the other cases reported had hypodontia as marked as in these brothers (fig 2). The milk teeth did erupt but were rudimentary and were not replaced by permanent dentition, of which there was no evidence on $x$ ray. Although the age of onset of the neurological features is not clearly documented in every case, the reported range at which clinical evidence of these were observed varies between $3^{2}$ and $14^{1}$ years.

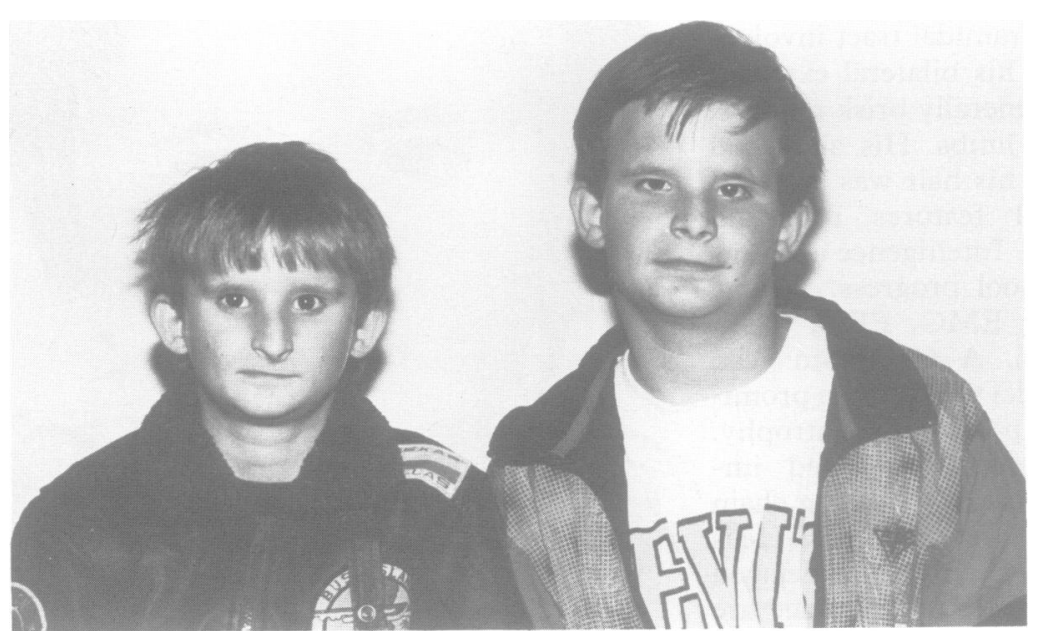

Figure 3 Case 1 (right) and case 2 (left) aged 14 and 12 respectively.

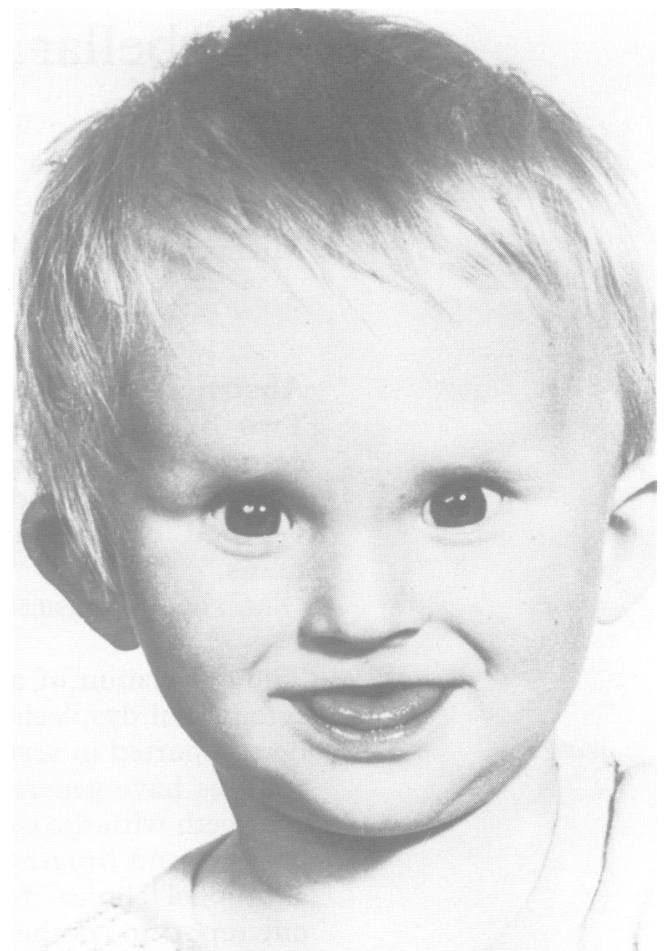

Figure 4 Case 2 aged 4. Note sparse hair and hypodontia.

Hypogonadism and short stature were documented in the cases of Rushton and Genel. ${ }^{1}$ Stature was normal in the other cases described, as it was in these brothers. Puberty is delayed in case 1 of this report which may possibly be related to his orchidopexy.

The parents of our sibship are neurologically normal and the family history unremarkable, in contrast to the report of Klingmuller and Kirchhof. ${ }^{3}$ These authors described four affected males among a sibship of five males and six females, born to a father with reported Friedreich's ataxia and a mother whose brother was said to have a 'movement disorder'. Like our patients, these boys had normal stature, hyperreflexia, and cerebellar signs, but had more severe hair involvement and much less severe dental involvement than we describe.

From these reports it appears that genetically determined conditions combining ectodermal dysplasia and spinocerebellar pathology do exist, although no two reports are exactly alike. The late onset of the ataxia delays

Comparison of present and previously reported cases.

\begin{tabular}{lccccc}
\hline & Case 1 & Case 2 & Ref 1 & Ref 2 & Ref 3 \\
\hline Teeth abnormal & + & + & + & + & + \\
Hair abnormal & + & + & + & + & + \\
Nails normal & + & + & + & + & + \\
Sweating normal & + & + & + & + & + \\
OFC normal & + & + & + & + & + \\
Mental retardation & - & - & + & - & - \\
Onset of ataxia & 13 & 12 & $? 14$ & 3 & $? 13$ \\
Hyperreflexia & + & + & + & - & + \\
Deafness & - & - & + & - & - \\
Cerebellar atrophy on & & & & & \\
$\quad$ CT & + & + & + & ND & ND \\
Short stature & - & - & + & - & - \\
Hypogonadism & UDT & UDT & + & - & - \\
Midfacial hypoplasia & + & + & + & + & + \\
\hline
\end{tabular}

$\mathrm{ND}=$ not done. $\mathrm{UDT}=$ undescended testes. 
the clinical recognition of the condition. The consanguinity among the parents and the different sexes of the affected children confirm the likely autosomal recessive nature of the inheritance in the Rushton and Genel report. ${ }^{1}$ Lack of information and uncertainty as to the neurological problems in the parents mean that it is impossible to comment on the inheritance in the family of Klingmuller and Kirchhof. ${ }^{3}$ Further delineation of this rare condition or group of conditions must await the recognition and reporting of other families.
The authors wish to thank Avril Fowler for linguistic assistance.

1 Rushton AR, Genel M. Hereditary ectodermal dysplasia, olivopontocerebellar degeneration, short stature and hypogonadism. I Med Genet 1981;18:335-9.

2 Geormaneanu M, Walter A, Lazarescu P. Spinocerebellare ataxie assoziiert mit Monilethrix, eigenartigen Gesichtszugen und Zahnanomalie. Monatsschr Kinderheilkd 1976;124:647-9.

3 Klingmuller G, Kirchhof JKJ. Uber die erbliche ektodermale Dysplasie mit Anhidrosis und cerebellarer Heredoataxie im Sinne einer Freidreichschen Erkrankung. Hautarzt 1954;5:351-7.

4 Harding AE. The hereditary ataxias and related disorders. London: Churchill Livingstone, 1984. 